\title{
Uma avaliação do Índice de Gestão Descentralizada do Programa Bolsa Família
}

\author{
Fábio Resende de Araújo \\ Universidade Federal do Rio Grande do Norte (UFRN) \\ Maria Arlete Duarte de Araújo \\ Universidade Federal do Rio Grande do Norte (UFRN) \\ Fabia Jaiany Viana de Souza \\ Instituto Federal de Educação, Ciência e Tecnologia do Rio Grande do Norte (IFRN) \\ Diego Fiel Santos \\ Universidade Federal de Juiz de Fora (UFJF) \\ Murilo Barreto Santana \\ Universidade Estadual de Santa Cruz (UESC)
}

\begin{abstract}
O objetivo deste artigo é investigar a relação entre o número de famílias participantes do Programa Bolsa Família (PBF) nos municípios do Nordeste e os indicadores de avaliação do PBF — os subcomponentes do Fator de Operação do Índice de Gestão Descentralizada (GD). Utilizou-se o coeficiente de Correlação de Pearson com dados de 1.705 municípios. As correlações com significância estatística foram entre Número de Famílias do PBF e todos os subcomponentes do IGD, entre IGD saúde e os demais subcomponentes do IGD e entre o IGD educação e a Atualização de Cadastro. A conclusão é de que maior número de famílias beneficiárias do PBF leva a um decréscimo dos seus indicadores de monitoramento, o que aponta para as fragilidades de gestão nos municípios e coloca um enorme desafio para a articulação do PBF com outras ações importantes como a saúde e a educação.
\end{abstract}

Palavras-chave: transferência de renda condicionada; Bolsa Família; Índice de Gestão Descentralizada.

Una evaluación de Índice de Gestión Descentralizada del Programa Bolsa Família

El objetivo de este artículo es la investigación de la relación entre el número de familias de este programa en los ayuntamientos de la región Nordeste y sus indicadores de evaluación del PBF - los subcomponentes del Factor de Operación de Índice de Gestión Descentralizada (IGD). De este modo, fue utilizado el Coeficiente de Correlación de Pearson con los datos de 1705 ayuntamientos. Las cor-

DOI: http://dx.doi.org/10.1590/0034-7612119242

Artigo recebido em 18 jun. 2013 e aceito em 6 out. 2014.

(c)) BY-NC 
relaciones con significancia estadísticas fueron entre el Número de Familias do PBF y todos los subcomponentes del IGD, entre IGD salud y los demás subcomponentes del IGD y entre el IGD educación e la Actualización de Registros. La conclusión es que un mayor número de familias beneficiarias del PBF conduce a una disminución de sus indicadores de seguimiento, lo que apunta a la fragilidad de la gestión en los municipios y plantea un gran desafío para las articulaciones del PBF con otras acciones importantes como la salud y la educación.

Palabras clave: transferencia de renta condicionada; Bolsa-Família; Índice de Gestión Descentralizada.

An assessment of the Decentralized Management Index of Bolsa Família Program

The aim of this paper is to investigate the relationship between the number of participating families in the Bolsa Família program (BFP) in the Northeast municipalities and their respective indicators of evaluation of BFP - the subcomponents of Index Operation Factor of Decentralized Management (IDM). We used Pearson Correlation coefficient with data from 1705 counties. The correlations with statistically meaning were between the number of families of the BFP and all the subcomponents of the IDM, among IDM health and other subcomponents of IDM, and between IDM education and Registration Update. The conclusion is that a greater number of families benefited from the BFP leads to a decrease of its monitoring indicators, which points to the fragility of management in municipalities, creating a major challenge for BFP' articulation with other important actions, such as health and education.

KeYwoRDs: conditional income transfer; Bolsa Família; Decentralized Management Index.

\section{Introdução}

Considerado o carro-chefe da política social brasileira desde 2003, o Programa Bolsa Família (PBF) passou a ter status determinante na política social em meio a um polarizado debate de como se instituiu como tal. Tendo como objetivos o enfrentamento da fome e da miséria no país e a promoção da emancipação das famílias mais pobres, tem alcançado 13,8 milhões de famílias participantes e contabilizado mais de 50 milhões de beneficiários (1/4 da população brasileira) em 2012.

O PBF, principal integrante do Plano Brasil sem Miséria - estratégia social do governo de Dilma Rousseff (2011-14) —, está estruturado em três eixos: Inclusão Produtiva, Garantia de Renda e Acesso a Serviços. O PBF pretende promover esses eixos, respectivamente, pelas seguintes ações: 1) Estímulo à inserção em programas denominados "Portas de Saída" como o Pronatec (implementado a partir de 2011); 2) Repasse mensal de valor monetário; 3) Exigência de condicionalidades obrigatórias para permanência no Programa, buscando a inserção das famílias em serviços básicos de saúde a exemplo da imunização infantil, pré-natal e avaliação nutricional, assim como a manutenção de frequência escolar para as crianças das famílias beneficiárias.

Para implementar tais ações se faz necessário adotar a descentralização vertical (articulação entre União, estados e municípios) e horizontal (articulação entre setores de assistência social, saúde, educação e trabalho). A respeito da descentralização vertical há uma distinção 
das funções entre os entes governamentais: o governo federal planeja, monitora e avalia as ações do programa e os municípios executam. Quanto à descentralização horizontal, ou intersetorialidade, o Programa atribui à Assistência Social a coordenação geral do Programa, por meio do Ministério do Desenvolvimento Social e Combate à Fome (MDS). Já às Secretarias Municipais de Assistência Social é atribuída a responsabilidade de implementação de processos básicos (cadastro e atualização destes) e complementares (acompanhamento familiar, portas de saída, busca ativa por novos beneficiários, apuração de irregularidades, entre outros) sob monitoramento e apoio das Secretarias Estaduais da mesma agenda. As condicionalidades da saúde e da educação são atribuições dos Ministérios da Saúde e da Educação que planejam e monitoram a implementação dos acompanhamentos.

A responsabilidade compartilhada por diferentes entes do governo é fundamental, não por motivos constitucionais, mas pelo fato de que sem esse arranjo a gestão do Programa se torna inviável. A conjugação de ações de diferentes setores por meio das condicionalidades é vista também como premissa básica para o atingimento do seu objetivo de promover o acesso a serviços básicos. O esperado é uma ação integradora de diferentes agendas e de alta capilaridade gerencial em estados e municípios.

Devido à complexa interação entre variáveis relacionadas com o combate da extrema pobreza, as avaliações de programas dessa natureza passam a ter um caráter multidisciplinar, abrangendo diversas áreas do conhecimento com o uso de ferramentas de mensuração da eficácia e efetividade de resultados a que essas ações se propõem. Os instrumentos utilizados para mensuração dos resultados devem apresentar adequação aos objetivos propostos e proporcionar transparência para favorecer o controle social dessas ações.

A avaliação integrada da eficácia desse arranjo de ações em estados e municípios é feita através do Índice de Gestão Descentralizada (IGD). O IGD procura ser um indicador objetivo, sintético e transparente que estimula boas práticas de gestão por meio do repasse de recursos de apoio à gestão proporcional ao número de famílias cadastradas na localidade e o desempenho do cumprimento dos itens básicos para funcionamento do Programa (cadastro, atualização de cadastro e as condicionalidades da educação e da saúde), expresso em um índice numérico com variação de 0 a 1 .

Apesar de ser um indicador de relevância com poder significativo de explicação da gestão do PBF, o IGD é pouco explorado pela literatura. Os estudos que o abordam são os de Monteiro, Ferreira e Teixeira (2009), Estrella e Ribeiro (2008) e Pedroso, Calmon e Bandeira (2009), que, apesar de pontuais, despertam considerações relevantes sobre a possibilidade de inferência dos determinantes gerenciais do Programa. Tais estudos serão considerados referências para análise dos resultados obtidos neste trabalho.

Assim, este artigo objetiva verificar a relação entre o número de famílias beneficiárias do PBF nos municípios da região Nordeste e os indicadores numéricos de avaliação do Programa (os componentes do Índice de Gestão Descentralizada) e a existência de correlação entre os subcomponentes do IGD.

Para tanto, o artigo está estruturado em seis seções, incluindo esta introdução. Na próxima seção discorre-se sobre o histórico, a estrutura do PBF e as repercussões diretas para sua 
execução. A seção três discute o Índice de Gestão Descentralizada (IGD), principal indicador de avaliação do PBF e objeto do presente estudo. Na seção quatro detalha-se a metodologia adotada na pesquisa. A seção cinco trata dos resultados do estudo com considerações sobre a influência da demanda de famílias no desempenho da assistência prestada evidenciado pelo IGD e seus componentes. A seção seis apresenta as principais conclusões.

\section{A gestão do Programa Bolsa Família: os desafios da implementação das condicionalidades em contexto federativo}

Considerado um divisor de águas no histórico das políticas de proteção social no Brasil, marcado por reveses e momentos de estagnação oriundos da instabilidade econômica, o PBF está em sintonia com a tendência de Programas de Transferência de Renda Condicionadas (PTRC) que vêm se estabelecendo nos países em desenvolvimento, principalmente na América Latina. ${ }^{1}$

O PBF foi instituído pela Lei no $n^{-10.836 / 2004}$ e regulamentado pelo Decreto $n^{\circ}$ $5.209 / 2004$, com o objetivo de reduzir a pobreza e as desigualdades existentes por meio da transferência condicionada de recursos monetários para as famílias que vivem em estado de extrema pobreza. Os critérios de elegibilidade do programa são: famílias que possuem renda mensal per capita entre $\mathrm{R} \$ 70,00$ e R $\$ 140,00$ por pessoa com crianças ou adolescentes de até 17 anos; famílias com renda mensal de até $\mathrm{R} \$ 70,00$ por pessoa qualquer que seja a idade dos membros da família.

O PBF foi criado em 2003 por meio da unificação dos primeiros programas sociais de TCR, tais como o Bolsa Escola e Bolsa Alimentação que tiveram vida curta entre 2001 a 2003, últimos anos do governo de Fernando Henrique Cardoso. Segundo Zimmermann (2006), muitas vezes, tais programas chegavam a concorrer entre si quando da liberação de recursos. Os sistemas de informação dos programas que originaram o PBF eram separados e não se comunicavam, de modo que uma família poderia receber todos os diferentes benefícios, enquanto outra vivendo em condições iguais poderia não receber transferência alguma (Zimmermann, 2006; Soares e Satyro, 2009).

Os projetos que originaram o PBF, caracterizados por uma gestão centralizada e por um alto grau de focalização, foram implementados por distintos ministérios e secretarias, não havendo uma ação interministerial, o que impedia a otimização das ações e resultava em alto custo operacional, pouca efetividade e falta de referência a direitos. O quadro 1 resume as características dos programas existentes antes do PBF.

Junto com a unificação dos programas houve o aumento da cobertura de beneficiários e a criação de um cadastro único de informações para os programas sociais do país. As antigas

\footnotetext{
${ }^{1}$ Exemplos: Argentina (Jefes y Jefas); Chile (Chile Solidário); Peru (Juntos); Nicarágua (Red de Protección Social - RPS); México (Oportunidades/Progresa); Colômbia (Familias em acción); Honduras (Programa e Asignación Familiar) e Jamaica (Programme of Advancement Through Health and Education).
} 
condicionalidades do Bolsa Escola e do Bolsa Alimentação passaram a ser, respectivamente, a condicionalidade da educação e da saúde do PBF.

Quadro 1

Descrição dos programas sociais que originaram o Programa Bolsa Família

\begin{tabular}{|c|c|c|c|}
\hline PROGRAMA & MINISTÉRIO & OBJETIVO & CRIAÇÃO \\
\hline Bolsa Escola & Ministério da Educação & $\begin{array}{l}\text { Permitir o aumento da frequência escolar através de uma } \\
\text { contrapartida que consistia na frequência mínima de } 85 \% \text { à } \\
\text { escola, no ano, para crianças de seis a } 15 \text { anos. O benefício era } \\
\text { concedido a famílias cuja renda per capita se situava abaixo de } \\
R \$ 90,00 \text {, e o valor da bolsa era de } R \$ 15,00 \text { por criança, com } \\
\text { um teto de } R \$ 45,00 \text { por família. }\end{array}$ & 2001 \\
\hline Bolsa Alimentação & Ministério da Saúde & $\begin{array}{l}\text { Estimular gestantes, nutrizes e crianças menores a participarem de } \\
\text { atendimento pré-natal, consultas pós-parto e atividades educativas } \\
\text { de saúde. O valor da bolsa era de R\$ 15,00 por criança entre zero } \\
\text { e seis anos, com teto de } R \$ 45,00 \text { por família. }\end{array}$ & 2001 \\
\hline Cartão Alimentação & Ministério da Saúde & $\begin{array}{l}\text { Transferência de } \mathrm{R} \$ 50,00 \text { para famílias cuja renda per capita } \\
\text { não alcançasse meio salário mínimo, e os recursos deveriam ser } \\
\text { usados exclusivamente na compra de alimentos. }\end{array}$ & 2003 \\
\hline
\end{tabular}

Fonte: Elaboração dos autores a partir de dados do Ministério do Desenvolvimento Social e Combate à Fome (2011).

Considerando a concepção de contrapartida, os PTRC são uma forma de combinar indenização e inserção social com engajamento pessoal dos beneficiários (Castro et al., 2009). As condicionalidades do PBF tentam inserir a população-alvo nas duas maiores, principais e mais complexas políticas sociais do país: educação e saúde. O objetivo é uma dupla responsabilização - das famílias pelo compromisso assumido e do poder público em assegurar a oferta desses serviços básicos.

Com o propósito de romper com a pobreza entre gerações, constitui um dever dos que recebem o benefício (regulamentado pela Portaria GM no 321/2008), visitas semestrais aos centros e postos de saúde, assim como assegurar que seus filhos frequentem regularmente a escola. Caso não sejam cumpridos tais requisitos, o benefício é suspenso, podendo até ser cancelado.

Coerente com a concepção multissetorial da diminuição da pobreza, o acompanhamento das condicionalidades se dá em três setores (educação e saúde na execução e monitoramento das condicionalidades e assistência social na atualização e validação dos cadastros) nos três níveis federativos do Brasil. O monitoramento da contrapartida da educação do PBF é consolidado pelo MEC e as informações referentes à contrapartida de saúde pelo Ministério da Saúde. O Ministério do Desenvolvimento Social e Combate à Fome, por sua vez, faz a cobrança aos beneficiários quando descumpridas as condicionalidades.

O descumprimento das condicionalidades se expressa nas situações de frequência inferior a $85 \%$ das crianças em idade escolar sem justificativa por 2 meses para a contrapartida da 
educação. Para a contrapartida da saúde não existe padronização do número mínimo de vezes que a família possa se ausentar do acompanhamento feito a cada seis meses. Fica a cargo do município essa definição.

Enquanto a transferência monetária é centralizada no governo federal chegando até a população por meio da alta capilaridade da rede bancária, as condicionalidades são descentralizadas, ficando a gestão de sua implementação e monitoramento a cargo de cada município, sendo necessária uma descentralização administrativa. A legislação do programa ratifica a responsabilidade do município quanto à oferta de serviços e de gestão do acompanhamento do cumprimento das obrigações das famílias beneficiadas. A Portaria no 321 , de 29 de setembro de 2008, do MDS regulamenta a gestão das condicionalidades do PBF, que consiste nas atividades e procedimentos descritos no quadro 2.

Quadro 2

Procedimentos e atividades que compreendem a gestão das condicionalidades do PBF

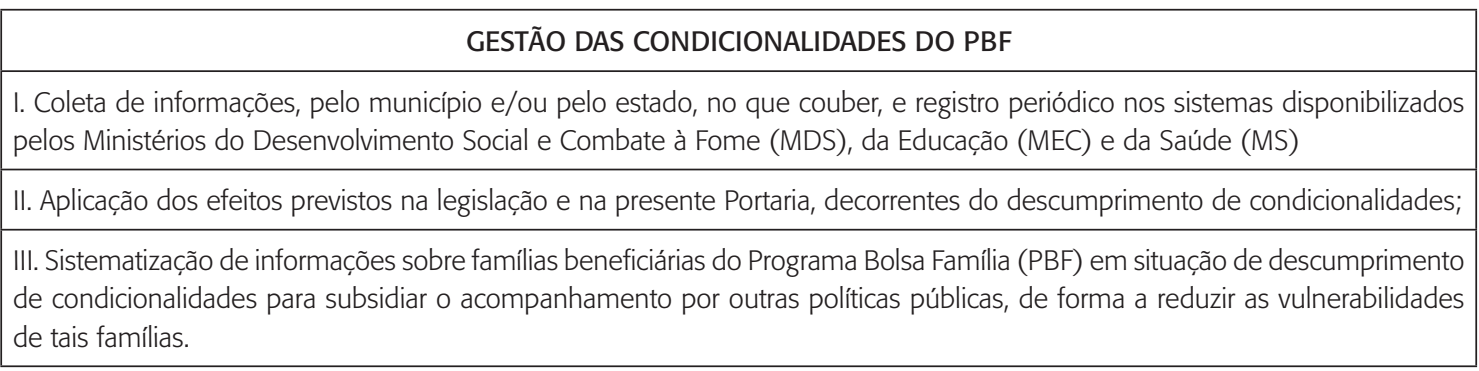

Fonte: Elaborado a partir da Portaria № 321, de 29 de setembro de 2008, do MDS.

Dessa forma, o PBF tem em sua gestão dois elementos principais para o alcance dos seus resultados: a intersetorialidade e a cooperação federativa. Para Lício, Mesquita e Curralero (2011), ambos os aspectos no modo de gerir são cada vez mais frequentes na administração pública, sendo manifestações da complexidade da gestão de políticas sociais em contextos federativos contemporâneos. Nos PTRC esses aspectos são imperativos, uma vez que a pobreza compreendida a partir de seu caráter multidimensional requer para sua superação, além do trabalho conjunto dos entes federativos (União, estados e municípios), uma coordenação orientada a buscar a integralidade do atendimento às populações mais pobres a partir da integração das políticas sociais voltadas a esse público (Curralero e Alonso, 2011).

Para Chiechelski (2007), a descentralização vertical (cooperação federativa) e a horizontal (intersetorialidade) são fatores críticos do PBF uma vez que diferentes esferas de governo são permeadas por interesses distintos. Para Coelho (2009), a descentralização setorial assim como a administrativa exigem capacidades de negociação e de flexibilidade para que os conflitos gerados pela individualidade de interesses sejam trabalhados, ao mesmo tempo que sejam consideradas as particularidades dos envolvidos e que as ações são viabilizadas. 
As inovações gerenciais como a descentralização (horizontal e vertical) e condicionalidades tentam diferenciar o PBF das políticas emergenciais de combate à pobreza que são intensamente criticadas por seu baixo poder em diminuir seus determinantes. Contudo, muito se questiona sobre o real alcance das ações do Programa, pelo fato de estar apoiado em uma rede de assistência existente e com muitas debilidades.

Cobo (2012) indica que muitos países que atualmente adotam o PTRC não possuem a capacidade financeira e administrativa para gerenciar sistemas complexos de controle de cumprimento de condicionalidades que são característicos desses programas. Tal acompanhamento esbarra na questão da oferta dos serviços, escolas, unidades de saúde, profissionais e transporte públicos que levam a uma precária operacionalização dessas atividades. Dias (2008) enfatiza que os programas de PTRC não deveriam exigir o cumprimento de condicionalidades, visto que os países que os implementam, ainda em desenvolvimento, não possuem o mínimo para subsidiar os serviços básicos.

Boschetti (2006) enfatiza que, em termos gerais, a seguridade social no Brasil associa, ao mesmo tempo, universalidade e seletividade, centralização e descentralização, distributividade e redistributividade, gratuidade e contributividade. Mota, Amaral e Peruzzo (2012) indicam que esse hibridismo é justamente o principal elemento diferenciador que vai caracterizar a política social contemporânea e trazer desafios a sua gestão, por envolver uma mescla entre sistemas universais básicos, formas individualizadas de proteção privada e programas focalizados em extratos sociais menos favorecidos.

Para Pastorini (2006), nessa nova modalidade de intervenção social denominada por alguns de "novo paradigma das políticas sociais", o Estado delega parte de suas responsabilidades de proteção social para a sociedade civil e para o mercado, fazendo com que os aptos busquem por meio de seus próprios recursos a sua seguridade social ao mesmo tempo que tenta amparar de forma mínima os que não conseguem por si só atingir suas necessidades básicas.

Porém, os atuais PTRC optam por apoiar suas ações na estrutura já existente e debilitada das políticas ditas universais. Existe, portanto, uma incompatibilidade entre os dois sistemas que o PBF comunica: programas focalizados e políticas universais. As políticas de saúde e de educação, condicionalidades principais do Programa, pretendem basear-se nos princípios da universalidade, gratuidade, redistributividade e descentralização, porém a realidade é uma insuficiência desses serviços, resultando na formação de mercados que assistem parte da população quanto a estes serviços.

As ações do PBF são direcionadas a uma parcela da população específica (os extremamente pobres principalmente). Isso implica que irão existir regiões com maior concentração de famílias beneficiárias do que outras. Porém, a maior necessidade de assistência não é acompanhada da ampliação da rede de assistência à saúde e educação nessas localidades, mesmo que seja esperado que a participação no Programa pressione o aumento de atendimentos nessas localidades. Dessa forma, as ações de saúde e educação não alcançam o mesmo ritmo de expansão do PBF.

Somam-se a esses aspectos as diferenças sociais, econômicas, demográficas e históricas entre os municípios brasileiros que são submetidos a uma forma-padrão de gerenciamento do Programa. Curralero e Alonso (2011) apontam que, devido ao papel fundamental dos 
governos locais na implementação do PBF e da heterogeneidade existente em termos das instituições e capacidade da gestão municipal, observam-se muitas diferenças nos resultados alcançados no que se refere a um atendimento mais integral das famílias pobres.

Veloso e colaboradores (2011) indicam que, nas últimas três décadas, a gestão municipal se trata de um condicionante fundamental na formulação e na execução das políticas públicas no Brasil. Tal fato decorre da necessidade de provimento de bens e serviços públicos à população em virtude da descentralização federativa, da universalização dos direitos da cidadania e da instituição da seguridade social. Os autores apontam que existem diferenças entre os municípios que devem ser consideradas para compreender como a gestão municipal pode ser uma instância definidora do êxito das políticas públicas. Entre as razões que originam estas diferenças destacam três argumentos principais:

、 Diferença entre a arrecadação e o contingente populacional dos municípios: os municípios que geram maior receita própria também são aqueles que reúnem o maior contingente populacional, enquanto os municípios que não possuem base econômica desenvolvida são mais dependentes de recursos provenientes de transferências da União e possuem menor contingente populacional. O resultado da conjugação desses fatores é uma acentuada assimetria na disponibilidade de recursos por habitante.

• Criação de novos municípios: a multiplicação de municípios acentua as desigualdades existentes. A multiplicação de novos municípios se deu em detrimento das áreas mais pobres dos municípios desmembrados, pois os novos geralmente se localizavam nas zonas de maior concentração das atividades econômicas.

- Separação entre as tendências de concentração espacial dos recursos e de concentração das demandas por esses recursos: a descentralização fiscal tende a favorecer os municípios menores, porém a demanda tende a se concentrar nos centros urbanos, devido ao ritmo de urbanização e à metropolização da pobreza, combinados com maiores custos de solução dos problemas enfrentados que exigem maior complexidade tecnológica. Dessa forma, as atenções do Estado deveriam voltar-se com prioridade para as populações menos favorecidas economicamente localizadas nos centros urbanos, o que não é observado no atual sistema de transferências.

Portanto, a gestão do PBF não pode ser vista de modo isolado. As condicionalidades só poderão ser feitas mediante a capacidade organizativa dos municípios e dos serviços que garantam a inserção das famílias em ações básicas de educação e saúde. Neste sentido, Silva (2008) aponta como limite para a implementação das condicionalidades a insuficiência quantitativa e de qualificação de recursos humanos, acrescido da insuficiência de recursos financeiros e institucionais na maioria dos municípios brasileiros, além da fragilidade ou ausência de uma rede de serviços sociais locais.

Veloso e colaboradores (2011) indicam que a capacidade dos municípios trata-se de uma condição prévia para a eficiência. A capacidade de gestão pode ser definida pelos autores como a existência de condições e parâmetros que possibilitem as entidades gerir recursos, pessoas e capital físico. 
A importância que os municípios têm na execução das políticas públicas exige, cada vez mais, que suas competências administrativas estejam orientadas para o resultado das políticas públicas. Quanto ao caso do PBF, existem questionamentos quanto à efetividade do Programa uma vez que suas condicionalidades são os elementos diferenciadores das demais políticas de transferência de renda e que podem ser inviabilizadas pela estrutura já existente nas localidades.

O monitoramento das condicionalidades, somado à verificação de conformidade de processos básicos de atualização e validação de cadastro dos beneficiários, constitui a avaliação permanente e institucionalizada pelo PBF que é representada por um índice numérico denominado Índice de Gestão Descentralizada (IGD). Sua avaliação pretende verificar em que medida os municípios implementam o Programa, superando os impasses anteriormente citados.

\section{Avaliação da gestão das condicionalidades: Índice de Gestão Descentralizada (IGD)}

Uma política pública de grande cobertura que passou em um curto prazo por expansões significativas (de 3,6 milhões de famílias, no início em 2003, para 13,2 milhões de famílias, em 2012 ) necessita de mecanismos de avaliação descentralizados e que sejam efetivos para mensurar o alcance dos objetivos esperados. Segundo Costa e Castanhar (2003), a avaliação sistemática de políticas públicas deve ser um mecanismo contínuo do ciclo dessas, pois se trata de um instrumento fundamental para alcançar melhores resultados e proporcionar uma melhor utilização e controle dos recursos aplicados, contribuindo para um processo de tomada de decisão mais bem fundamentado e resultando em uma gestão pública mais eficaz.

Um dos principais tipos de avaliação é a partir de objetivos. Para elucidar essa tipologia que difere as avaliações de acordo com seus objetivos é necessária a compreensão da diferença semântica dos termos que relacionam processos e resultados: eficácia, eficiência e efetividade. O Quadro 3, adaptado de Draibe (2000), sintetiza a diferença entre as terminologias dessas medidas de desempenho que são objetos de estudo avaliativos.

\section{Quadro 3}

Diferenciação semântica dos termos eficácia, eficiência e efetividade

\begin{tabular}{|clc|}
\hline INDICADOR & \multicolumn{1}{c|}{ DEFINIÇÃO } & TIPO DE AVALIAÇÃO \\
\hline Eficácia & $\begin{array}{l}\text { A relação entre características e "qualidades" dos processos e sistemas de sua } \\
\text { implementação e os resultados a que chegam. }\end{array}$ & Avaliação de processo ou \\
Eficiência & $\begin{array}{l}\text { Qualidades de um programa, examinados os parâmetros técnicos de tempo } \\
\text { e custo. }\end{array}$ & formativa \\
Efetividade & Relação entre objetivos e meta com impacto e efeitos. & Avaliaço \\
\hline
\end{tabular}

Fonte: Elaborado a partir de Draibe (2000).

Com relação à classificação dos tipos de pesquisas de acordo com seu propósito, Garcia (2000) e Subirats (1994) realizam a distinção em dois grupos: Avaliação de processos que visa à 
aferição da eficácia (se o programa está sendo implementado conforme seus objetivos, diretrizes e prioridades e se seus produtos estão atingindo as metas previstas com a necessária eficiência). A segunda é a Avaliação de impactos que diz respeito aos efeitos do programa sobre a populaçãoalvo (verificar se as transformações primárias e/ou secundárias na realidade são atribuíveis às ações dos programas, estabelecendo as devidas relações de causalidade). A avaliação de impacto tem uma ambição mais ampla e complexa. Ambas exigem trabalho de campo, um largo tempo para a realização, um número razoável de pesquisadores e apresentam custos elevados.

O PBF possui apenas uma forma de avaliação institucionalizada, representada pelo IGD, que é caracterizada como uma avaliação de processo ou eficácia. Os estudos de impactos do programa ainda são tidos de forma pontual devido à dificuldade em isolar fatores para observar correlações de variáveis sociais.

O principal componente do IGD,$^{2}$ o Fator de Operação, trata da representação unificada de variáveis-síntese dos processos restritos à gestão municipal do Programa, sendo este formado por quatro subindicadores: cobertura do cadastro único, atualização do cadastro único, condicionalidade da Educação e condicionalidade da Saúde (Ministério de Desenvolvimento Social e Combate à Fome, 2012).

A cobertura do cadastro único trata do número de inscritos no cadastro do Programa com perfil de renda per capita em situação de pobreza e pobreza extrema no município em conformidade com os dados do censo mais atual do Instituto Brasileiro de Geografia e Estatística (IBGE). O percentual de alcance do cadastro das famílias nessa condição nos municípios representa um dos subindicadores do IGD total.

A atualização de cadastro consiste em verificar se as famílias que recebem o benefício permanecem sob a condição de pobreza, permitindo a sua participação no Programa. A atualização do cadastro, a cada dois anos, é um mecanismo adotado para que o PBF mantenha a focalização ao longo do tempo. A atualização é feita normalmente por meio dos agentes municipais do PBF que revisitam as famílias para verificarem se as condições de vida mudaram ou permaneceram as mesmas.

Segundo Soares e Satyro (2009), na prática, nem todos os municípios mantêm esse grau de agilidade, sendo comum famílias que passam muito tempo sem receber visitas do agente social. É crescente o número de municípios que adotam como estratégias chamadas onde os beneficiários levam ao cadastro único dos municípios seus documentos, como carteira de trabalho, para atualização das informações. Esse percentual de atualizações do total dos que recebem o benefício representa o subindicador que compõe o IGD total.

Outro mecanismo utilizado na atualização de cadastros é o cruzamento de banco de informações do Programa com bases de dados de fontes formais como as bases do Benefício da Prestação Continuada (BPC) e a Relação Anual das Informações Sociais (Rais) no intuito de apontar se há entre os beneficiários renda diferente da real (Soares e Satyro, 2009).

\footnotetext{
2 Desde 2010, além do fator de operação, denominado Fator I, existem outros três fatores: Fator II de Adesão ao Sistema Único de Assistência Social (Suas), Fator III de Informação da apresentação da comprovação de gastos dos recursos do IGD e Fator IV de Informação da aprovação total da comprovação de gastos dos recursos do IGD pelo Conselho Municipal de Assistência Social. Estes quando cumpridos apenas multiplicam o Fator I por 1; portanto, o Fator Operação é o componente principal do IGD (Ministério de Desenvolvimento Social e Combate à Fome, 2012).
} 
O cumprimento dos objetivos das condicionalidades e sua gestão de cadastros são o principal foco de avaliação do PBF.

A condicionalidade da educação objetiva que todas as crianças e adolescentes entre 6 e 15 anos devem estar devidamente matriculadas e com frequência escolar mensal mínima de $85 \%$ da carga horária. Já os estudantes entre 16 e 17 anos devem ter frequência de, no mínimo, $75 \%$.

A condicionalidade da saúde tem por objetivo idas semestrais aos estabelecimentos de saúde onde as famílias devem ser acompanhadas quanto à imunização das crianças, acompanhamento pré-natal das gestantes, assim como deve ser realizada antropometria (mensuração de peso e altura/comprimento) para monitoramento do estado nutricional dos indivíduos, verificando em que dimensão a insegurança alimentar grave está sendo combatida (Ministério da Saúde, 2011).

Além da oferta de serviços de educação e saúde, o envio de dados de adesão desses serviços pelos beneficiários é retratado como composição parcial do Fator de Operação. A variação dos subindicadores IGD-Educação e IGD-Saúde acontece de acordo com a frequência dos participantes do Programa nas escolas e nos serviços de saúde, respectivamente.

A composição do fator de operação do IGD coloca o cumprimento das condicionalidades como ponto determinante da execução do programa (compõe 50\% do índice), o que indica o intuito de valorizá-las. O acompanhamento das contrapartidas, como se percebe, é indicado relativo à frequência, porém não há nenhuma contribuição de mensuração da qualidade desses serviços. A composição do IGD não escapa do debate em torno das contrapartidas.

O IGD é um indicador de gestão numérico que pode variar até 1 . Existe tanto para municípios, denominado de IGD-M, como para estados, o IGD-E que trata da média dos IGD-M dos seus municípios. Quanto mais próximo do valor máximo estiverem os subindicadores que o compõem, mais qualidade terá a gestão de processos relacionados com a implementação do PBF. O repasse do recurso prevê incentivos às boas práticas de gestão como incremento de $10 \%$ do valor final dos recursos, caso os municípios comprovem cumprimentos de condutas previamente estabelecidas, como:

- 3\% proporcionais ao acompanhamento das famílias beneficiárias em situação de descumprimento de condicionalidades que estejam em processo de acompanhamento familiar;

- 3\% quando o município atender nos prazos estipulados demandas da Senarc referentes à apuração de eventuais irregularidades na execução local do PBF;

- $2 \%$ quando o município tiver $100 \%$ dos dados referentes à Gestão Municipal atualizados no Sistema de Gestão do PBF (SIGPBF) há menos de um ano;

- $2 \%$ quando o município apresentar pelo menos $96 \%$ de cartões do PBF entregues na data de apuração do IGD-M.

Portanto, o IGD é uma estratégia adotada pelo Ministério do Desenvolvimento Social e Combate à Fome com o propósito de mensurar a qualidade das ações empreendidas, para refletir o desempenho de cada gestão municipal e incentivá-las à obtenção de resultados qua- 
litativos e também para compor a base de cálculo do montante de recursos que cada uma deve receber a título de apoio financeiro. Desde sua criação o IGD passou por uma série de ajustes incrementais. ${ }^{3}$ Sua atual formatação é descrita na figura 1.

Até 2010, os recursos eram repassados apenas para a esfera municipal. Após a consolidação da Portaria no 256/2010, o MDS estabeleceu critérios e procedimentos para transferência de recursos financeiros também aos estados. O objetivo é dotá-los de condições materiais adequadas para as atividades de gestão do PBF sob sua responsabilidade. ${ }^{4}$ No Brasil o teto desse recurso em maio de 2010 foi de $\mathrm{R} \$$ 1.500.000,00 por mês, sendo os estados e municípios do Nordeste os principais beneficiados com mais de $50 \%$ desse valor.

Como condição básica para recebimento do recurso se faz necessário atingir os valores mínimos de 0,20 para cada uma das taxas do Fator de Operação (Fator 1) e 0,55 no cálculo do Fator de Operação, ou seja, após o cálculo, a média aritmética das taxas deve atingir valor $\geq 0,55$.

\section{Figura 1}

Síntese dos cálculos para obtenção do Î́ndice de Gestão Descentralizada utilizado no monitoramento do Programa Bolsa Família nas esferas estaduais e municipais

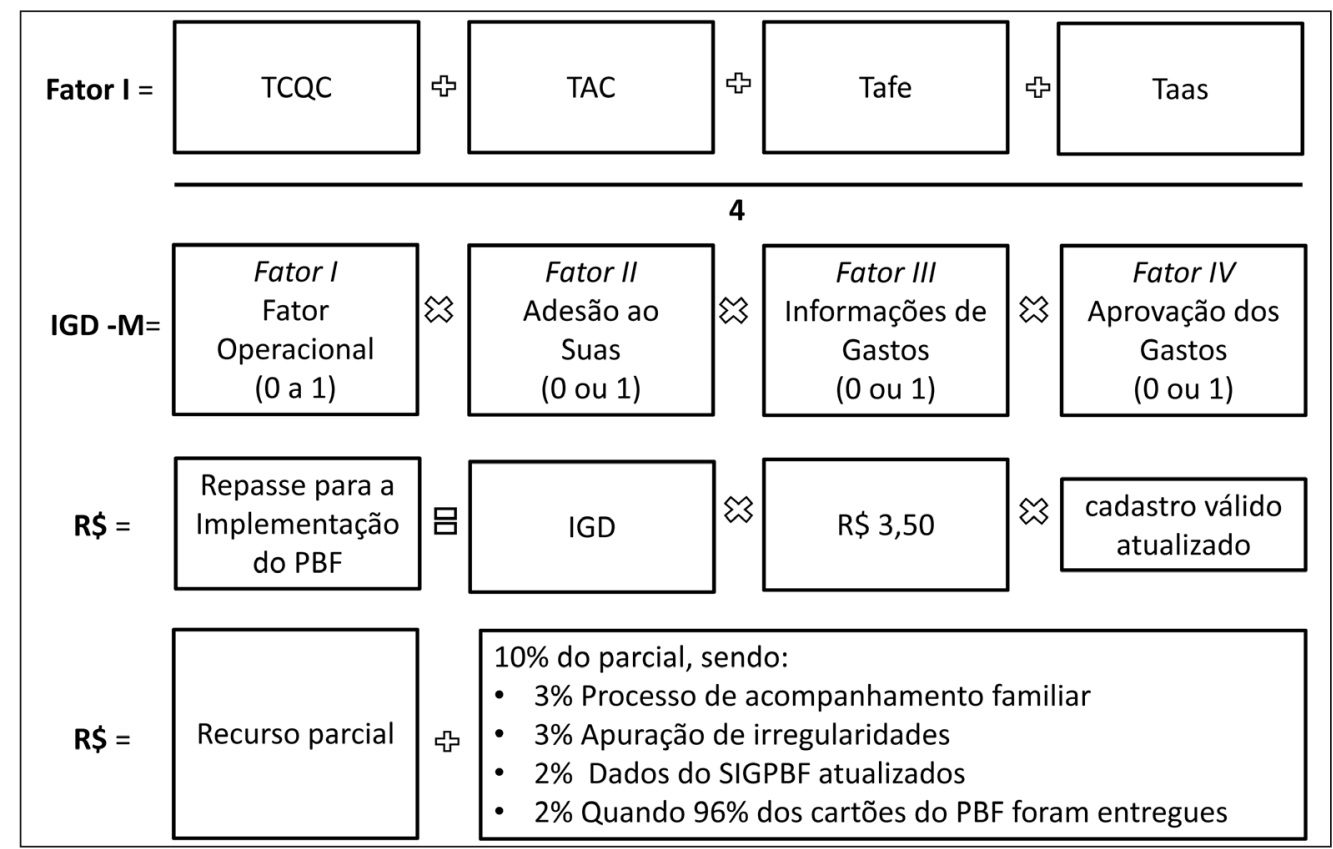

Fonte: Elaboração dos autores a partir do Ministério do Desenvolvimento Social e Combate à Fome (2012).

\footnotetext{
${ }^{3}$ IGD-M é regulamentado pela Portaria MDS/GM no 148, de 27 de abril de 2006 (alterada pelas Portarias MDS/GM $\mathrm{n}$ o 754, de 20 de outubro de 2010, e no 319, de 29 de novembro de 2011).

${ }^{4}$ Entre as principais atividades a serem desenvolvidas pelo recurso do IGD estão: acompanhamento das famílias beneficiárias em situação de maior vulnerabilidade social, identificação e cadastramento de novas famílias, implementação de programas complementares com atuação no apoio ao desenvolvimento das famílias beneficiárias, atividades relacionadas com o acompanhamento e a fiscalização do PBF, entre outras.
} 
Todos os municípios iniciaram a entrada no Programa em 2003, tendo sido criado o IGD em 2006. Os primeiros repasses consideraram os valores da avaliação do Programa no período anterior.

Chiechelski (2007) enfatiza que os modelos de avaliação, por maiores que sejam os esforços dos formuladores, são naturalmente limitados, pois deve-se considerar que as políticas sofrem influências das especificidades locais onde se implementa o programa, das variáveis fatoriais existentes nos municípios, da distribuição de competências e responsabilidades decorrente da descentralização administrativa, do objetivo da avaliação e do momento em que ela se processa.

Apesar de ser considerado um avanço a instituição de uma avaliação permanente do Programa, o IGD ainda possui limitações, caracterizando-se como um indicador quantitativo de avaliação de eficácia das principais atividades do programa. Os aspectos qualitativos da gestão e de indicadores de impacto da ação ainda não fazem parte do indicador. Considerase que os recentes ajustes incrementais do IGD, atrelado a outros incentivos flexíveis e condicionantes para o repasse dos recursos, representam um avanço. Mas entende-se que é um mecanismo pouco coerente atrelar esse indicador de avaliação à penalização monetária aos municípios que tenham piores resultados, pois na realidade estes devem ser os que possuem as maiores limitações para implementar o Programa.

\section{Metodologia}

A estruturação do PBF pretende ir além de uma política redistributiva de renda e aponta as condicionalidades como elementos fundamentais para se tornar uma política emancipatória. A eficácia dos mecanismos de implementação e avaliação do Programa é condição básica para o atingimento da sua finalidade. Neste artigo, o objetivo é contribuir para a avaliação do PBF, investigando a relação entre o número de famílias beneficiadas pelo Programa e seus principais indicadores de avaliação (os componentes do Fator de Operação do Índice de Gestão Descentralizada) nos municípios da região Nordeste, assim como avaliar a dependência entre os processos do Programa, por meio da análise da relação dos componentes do Fator de Operação do programa.

Santos e Magalhães (2012) propõem que a avaliação de programas sociais seja feita baseada na teoria do programa que subjaz à intervenção e não em um modelo de avaliação previamente normatizado. Não é possível fazer uma separação entre a gestão de uma política e o conceito que dela se tem. Entende-se que, ao se apresentar o programa com intenção de melhorar o capital social, o PBF tem em suas condicionalidades o principal desenho do programa, e o atual indicador de avaliação (IGD) e seus componentes permitem considerações que vão desde resultados que estes possam apresentar até limitações de suas constituições.

Mesmo diante do fato de ser um programa de amplitude nacional, optou-se por trabalhar com dados do Nordeste, pois, segundo Souza (2011), as regiões Norte e Nordeste apresentam as melhores focalizações, enquanto as Regiões Sul e Centro-Oeste apresentam 
focalizações mais baixas. Em Alagoas, por exemplo, de todos os beneficiários, cerca de 84\% são pobres. Por outro lado, em Santa Catarina, somente $47 \%$ do total dos beneficiários são pobres. ${ }^{5}$ Contribuiu ainda para a escolha da região o fato de o Nordeste concentrar 53,44\% do total de beneficiários.

O universo (população) do estudo são todos os municípios dos estados que compõem a região Nordeste do Brasil, sendo selecionados todos aqueles que apresentavam as informações necessárias para a realização dessa pesquisa nos bancos de dados utilizados para a coleta. O Nordeste é formado por 1.794 municípios. No entanto, 89 foram retirados do estudo por falta de informações, resultando em 1.705 municípios.

A escolha dos dados referentes aos municípios se baseia na própria estrutura do PBF. O papel mais importante é a responsabilidade pela identificação das famílias a serem beneficiadas, mediante o recolhimento das informações que compõem o cadastro. Ademais, os municípios são também responsáveis pelo acompanhamento das contrapartidas, além de serem os encarregados diretos pela oferta de boa parte dos serviços de educação e saúde necessários para que as famílias cumpram suas contrapartidas (Soares e Satyro, 2009).

A coleta de dados foi desenvolvida durante o período de $1^{\text {o }}$ a 30 de novembro de 2012, e consistiu na obtenção do número de famílias beneficiadas ${ }^{6}$ com o PBF e dos subíndices que compõe o Fator de Operação do IGD: validação de cadastros, de atualização de cadastro, de condicionalidade da saúde e de condicionalidade da educação, que foram retirados do sítio do Ministério de Desenvolvimento Social e Combate à Fome. Esses subindicadores, assim como o IGD geral, variam de 0 a 1 , e quanto mais próximo de 1 melhor é o atendimento do procedimento em análise. Também foram coletados do site do IBGE o tamanho territorial dos municípios e seu percentual de urbanização. Os dados são provenientes do Censo 2010.

Os dados obtidos foram digitados e armazenados no programa Microsoft Excel versão 2010. O banco de dados foi exportado para o software R versão 2.15.1, o qual foi utilizado neste trabalho como principal ferramenta para fazer análises estatísticas, em que todos os testes estatísticos foram implementados.

Pautando-se na estrutura do Programa e na teoria em que ele é fundamentado, discutese a hipótese de que o número de famílias beneficiárias influencia no alcance de melhores rendimentos dos subcomponentes do IGD. Como os subindicadores do IGD identificam se houve atualização de cadastro e se essas famílias cumprem as condicionalidades, é importante verificar o comportamento desses indicadores, considerando o número de famílias no município. O número de famílias que recebem o benefício é definido pelo IBGE, por meio do último censo no município. No caso das condicionalidades, o número dos que cumpriram é uma decisão dos beneficiários, mas também sofre influência da oferta do serviço e da dinâmica de envio das informações que depende dos municípios.

\footnotetext{
${ }^{5}$ Considerando a linha de pobreza de renda domiciliar per capita de R\$ 150,00 ao mês (IBGE).

${ }^{6}$ Neste trabalho não foi utilizado o número de beneficiados, mas sim o número de famílias. Esta é uma concepção do próprio programa instituída pela Lei no 10.836 .
} 
A intenção de utilizar o número de famílias como variável principal de análise é de verificar em que medida o aumento da complexidade do desenvolvimento de atividades do Programa influencia seus indicadores de desempenho. Apesar de seu relevante poder de explicação, essa variável não é considerada neste trabalho a única explicação para o desempenho das atividades do PBF, porém trata-se de um sinalizador da gestão do Programa. É importante registrar que os autores do trabalho, longe de pretenderem com este estudo defender qualquer tipo de redução na demanda, em função de possíveis debilidades estruturais na gestão que possam existir, objetivam com o mesmo evidenciar que o desenho do PBF precisa contemplar capacidades institucionais de gestão para que o Programa alcance seus resultados.

Para atestar tal hipótese foi realizado o coeficiente de Correlação de Pearson para medir o relacionamento linear entre duas variáveis — número de famílias e os subcomponentes do IGD: índice de atualização de cadastro, índice de validação de cadastro, índice de acompanhamento da condicionalidade da saúde e índice de acompanhamento da condicionalidade da educação. Para verificar se existe algum tipo de correlação entre os subcomponentes dos índices também foi realizada uma correlação entre eles.

\section{Resultados e discussão}

Conforme discutido, o IGD é um indicador síntese das principais ações do PBF pautado principalmente em atribuições básicas do Programa (cobertura qualificada e atualização cadastral) e nas condicionalidades que são as contrapartidas dos programas que originaram o PBF. Os subcomponentes que se referem às condicionalidades apenas retratam o aspecto quantitativo da participação dos beneficiários, não simbolizando efeitos qualitativos dos serviços prestados ou impacto que o Programa deva ocasionar. A tabela 1 apresenta os valores médios dos subindicadores por região do país.

Tabela 1

Distribuição dos valores do Índice de Gestão Descentralizada por regiões em maio de 2010

\begin{tabular}{|cccccc|}
\hline \multicolumn{6}{c|}{ ÍNDICE DE GESTÃO DESCENTRALIZADA DAS REGIÕES (IGD) } \\
\hline \multirow{2}{*}{ Região } & \multicolumn{4}{c|}{ Condicionalidades } & \multicolumn{3}{c|}{ Cadastro } & IGD \\
\cline { 2 - 6 } & Educação & Saúde & $\begin{array}{c}\text { Cobertura } \\
\text { qualificada }\end{array}$ & $\begin{array}{c}\text { Atualização } \\
\text { cadastral }\end{array}$ & Geral \\
\hline Brasil & 0,88 & 0,63 & 0,79 & 0,78 & 0,77 \\
Norte & 0,86 & 0,60 & 0,86 & 0,81 & 0,78 \\
Nordeste & 0,89 & 0,70 & 0,90 & 0,83 & 0,83 \\
Centro-Oeste & 0,86 & 0,59 & 0,67 & 0,76 & 0,72 \\
Sudeste & 0,88 & 0,54 & 0,64 & 0,71 & 0,69 \\
Sul & 0,89 & 0,63 & 0,65 & 0,68 & 0,71 \\
\hline
\end{tabular}

Fonte: Adaptada do Ministério do Desenvolvimento Social e Combate à Fome (2010). 
A tabela 1 apresenta o Nordeste com IGD geral de 0,83, indicando objetivamente que em média seus municípios não implementaram 17\% de atividades obrigatórias e básicas do Programa. Considerando seus subcomponentes, o IGD saúde é o de menor expressão $(0,70)$ e a cobertura qualificada o de maior expressão $(0,90)$. Considerando os subcomponentes das condicionalidades, os dados evidenciam pelo IGD saúde que $30 \%$ das famílias não cumpriram o acompanhamento nas unidades de saúde, e no IGD educação que 11\% das crianças em idade escolar não atingiram frequência de $85 \%$ neste ano na região Nordeste.

Esse menor resultado no IGD saúde entre os subcomponentes do fator de operação ocorre nas outras regiões do país. O fato aponta para uma não conformidade estrutural do próprio desenho do fluxo de informações da contrapartida.

Como principais possíveis fatores explicativos: 1) a dificuldade (?) de atualização do Sistema de Vigilância Alimentar e Nutricional — Módulo Bolsa Família (Sisvan), sistema responsável pela consolidação das informações da condicionalidade da saúde, de fluxo semestral. Esse fato é relevante, pois o perfil dessas famílias é não possuir casa própria, com uma intensa mudança de endereço, o que implica dificuldades de localização; 2) o fluxo de informação que apresenta entraves intermediários entre a coleta de informações nas unidades de saúde e as centrais de envio de informações on-line, devido à não informatização das unidades de saúde, o que aumenta as possibilidades de fraudes, sub-registros e pouca agilidade no envio; 3 ) pouca integração dessa condicionalidade com o cadastro único (Estrella e Ribeiro, 2008).

Apesar de ser o ambiente mais adequado para o acompanhamento, ainda se questiona se as Unidades Básicas de Saúde (UBS) possuem estrutura apta para tal serviço, pois segundo Relatório do Colóquio sobre Acompanhamento das Condicionalidades de Saúde do Programa Bolsa Família (Ministério da Saúde, 2011), 70\% das UBS do Brasil são consideradas inadequadas e precárias em sua estrutura física e capacidade de atendimento.

A dificuldade no monitoramento das famílias causada pela insuficiência de estrutura ainda é agravada pela insuficiência de equipes de PFS para a demanda. Apesar dos avanços quanto ao número de equipes de ESF nos últimos anos, ainda existem áreas sem cobertura de equipes do ESF, o que acaba sendo um entrave para a implementação das condicionalidades da saúde. Nota-se o quanto ainda é distante do ideal a cobertura da população pela ESF e pelos Agentes Comunitários de Saúde (ACS), pois em agosto de 2011 a média nacional era de 53,1\% e 63,7\%, respectivamente, segundo o Departamento de Atenção Básica do Ministério da Saúde.

Neste sentido, os acompanhamentos das famílias na saúde são uma das grandes dificuldades entre os procedimentos básicos do PBF. Com a constante expansão do número de beneficiários desde a sua criação, o monitoramento não teve uma evolução linear. Segundo o gráfico 1, é possível verificar períodos de intensificação dos percentuais de acompanhamentos, declínio e também de estagnação. 
Gráfico 1

Evolução do acompanhamento das condicionalidades de saúde do PBF entre 2005 e 2012

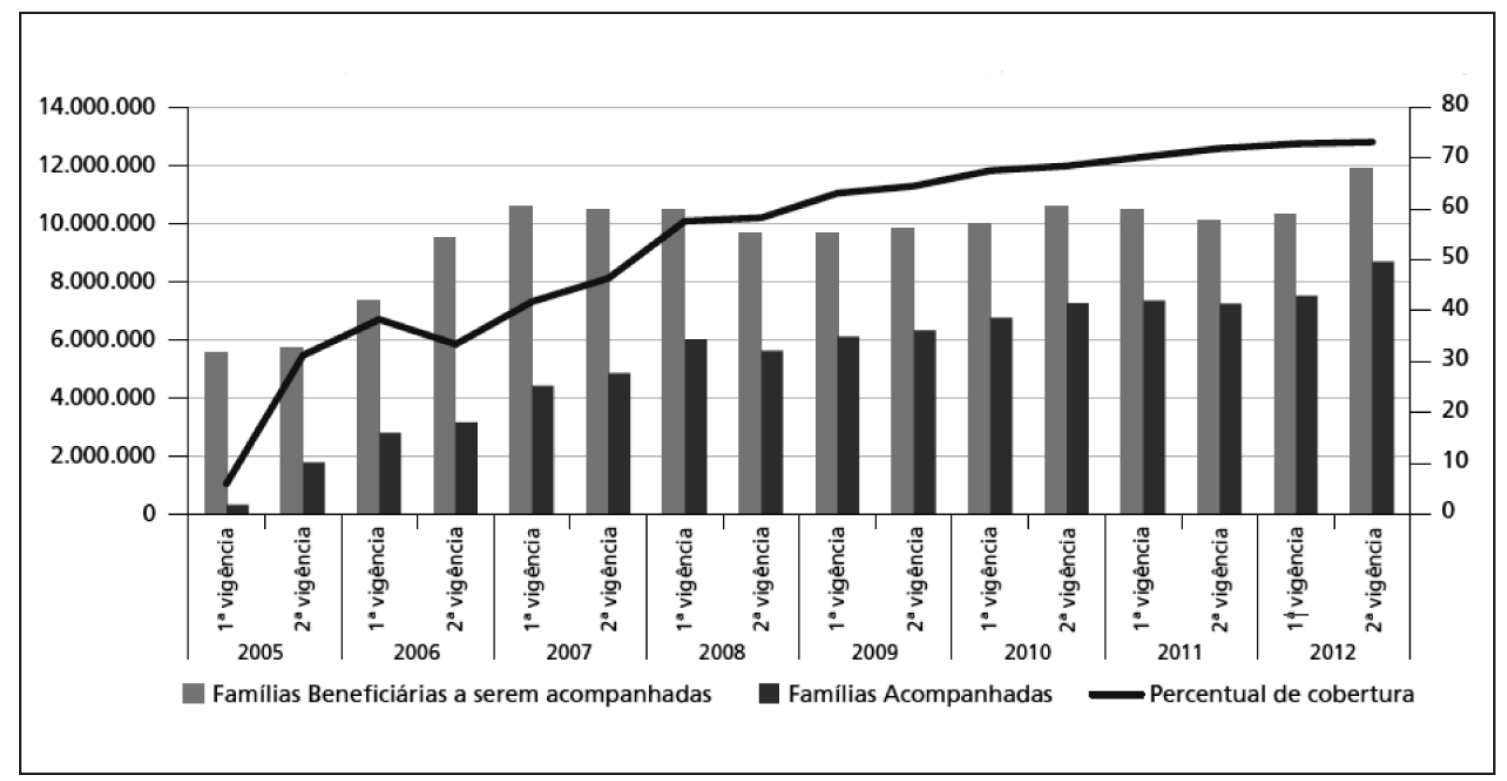

Fonte: Elaborado por Magalhães Junior, Jaime e Lima (2013) a partir do Sistema de Gestão do Programa Bolsa Família na Saúde.

Um marco histórico para a gestão das condicionalidades do PBF no SUS se deu quando foram pactuadas metas de cobertura de acompanhamento das condicionalidades de saúde do PBF, em 2008, no Pacto da Saúde. Em 2010, 18 estados alcançaram a meta pactuada de 70\% de acompanhamento do respectivo ano (Ministério da Saúde, 2011). Como ação para melhorar as práticas, a Organização Panamericana de Saúde e a Coordenação-Geral de Alimentação e Nutrição (CGAN) realizaram o Colóquio sobre Acompanhamento das Condicionalidades de Saúde do Programa Bolsa Família em 2011. Entre as principais conclusões foi colocada a necessidade de que haja ajustes em termos de descentralização e acompanhamento das condicionalidades para que o Programa amplie seu impacto. Percebe-se uma interação ainda frágil entre a Estratégia Saúde da Família e o Programa, o que minimiza as possibilidades de maior equidade na situação de saúde, na utilização de serviços e na qualidade da atenção.

Quanto à condicionalidade da educação, o sistema de envio de informações se diferencia do fluxo da informação da condicionalidade da saúde. O controle da contrapartida da educação é feito pelo Sistema de Presença de responsabilidade do MEC a partir de dados fornecidos pelo MDS. O envio dessas informações é bimestral, enquanto na condicionalidade da saúde é semestral (Cicero, Silva e Proença, 2013). Além disso, a informação do Sistema Presença é necessária para outras ações das escolas, enquanto as informações do Sisvan não se comunicam com outras ações de saúde. 
Em caso de descumprimento das condicionalidades, os efeitos são aplicados pelo MDS através do Sistema de Condicionalidades (Sicon). Normatizado pela Instrução Operacional $n^{\circ}$ 33 Senarc/MDS de 2009, o Sicon tem o propósito de apoiar a gestão intersetorial integrando informações dos sistemas do PBF presentes nos seguintes sistemas:

v Cadastro Único de Programas Sociais - Cadastro Único - que reúne as informações socioeconômicas das famílias com baixa renda e é a base de referência para a concessão de benefício do Programa Bolsa Família;

v Famílias beneficiárias do Programa Bolsa Família com dados de pagamento e a situação dos benefícios das famílias de acordo com os Sistemas de Pagamento operados pela Caixa;

v Sistemas de acompanhamento de condicionalidades setoriais da educação — Sistema de Frequência Escolar do PBF/MEC, saúde - Sistema Bolsa Família na Saúde/MS e assistência social - Sistema de Acompanhamento do Programa de Erradicação do Trabalho Infantil.

Para Paiva, Falcão e Bertholo (2013), o Sicon é um instrumento fundamental para a implementação interfederativa e intersetorial necessária ao Programa. Um sistema que permitiu trazer interoperabilidade às diferentes bases de dados do PBF, contribuindo para a adesão ao sistema e para a maior eficiência e efetividade das ações de acompanhamento de condicionalidades e das famílias do PBF.

A tabela 2 demonstra os resultados dos testes de correlação realizados com as variáveis do PBF em 1.705 municípios da região Nordeste e seus respectivos Valor-p. Como principais conclusões dos testes de Correlação de Pearson temos correlações significativas ao nível de 5\% entre Número de Famílias do PBF e todos os subcomponentes do IGD (ValCad, AtuaCad, IGDEdu, IGDSau), entre IGD saúde e os demais subcomponentes do IGD (ValCad, AtuaCad, IGDEdu) e entre o IGD educação e atualização de cadastro. Sendo todas estatisticamente diferentes de zero com confiança de 95\%.

Tabela 2

Teste de Correlação de Pearson de variáveis relacionadas ao Programa Bolsa Família em 1.705 municípios do Nordeste em julho de 2010

\begin{tabular}{|cccccc|}
\hline \multicolumn{5}{c|}{ CORRELAÇ̃̃O DE PEARSON } \\
\hline & NPBF & ValCad & AtuCad & IGDEdu & IGDSau \\
\hline Número de Famílias do & 1.000 & -0.247 & -0.097 & -0.123 & -0.192 \\
PBF & & & & 0.023 & 0.139 \\
Validação de Cadastro & -0.247 & 1.000 & -0.006 & 0.091 & 0.126 \\
Atualização de Cadastro & -0.097 & -0.006 & 1.000 & 1.000 & 0.137 \\
IGD Educação & -0.123 & 0.023 & 0.091 & 0.137 & 1.000 \\
IGD Saúde & -0.192 & 0.139 & 0.126 & & Continua
\end{tabular}




\begin{tabular}{|c|c|c|c|c|c|}
\hline \multicolumn{6}{|c|}{ CORRELAÇÃO DE PEARSON } \\
\hline \multicolumn{6}{|c|}{ Valor-p } \\
\hline & NPBF & ValCad & AtuCad & IGDEdu & IGDSau \\
\hline \multicolumn{6}{|l|}{$\begin{array}{c}\text { Número de Famílias do } \\
\text { PBF }\end{array}$} \\
\hline Validação de Cadastro & $<0.001$ & & & & \\
\hline Atualização de Cadastro & $<0.001$ & 0.7981 & & & \\
\hline IGD Educação & $<0.001$ & 0.3328 & $<0.001$ & & \\
\hline IGD Saúde & $<0.001$ & $<0.001$ & $<0.001$ & $<0.001$ & \\
\hline
\end{tabular}

Fonte: Dados da pesquisa.

Quanto à análise entre o número de famílias do PBF e os subcomponentes do IGD, verificou-se uma correlação negativa, indicando que quando uma cresce a outra decresce. Ou seja, o teste indica que, quanto maior o número de beneficiários, menores são os índices de cadastro, atualização e monitoramento das condicionalidades. Supõe-se que essa correlação negativa indica a capacidade limitada dos municípios em atender demandas maiores de beneficiários e aponta para a necessidade de forte investimento na capacidade de gestão dos municípios.

Essa relação negativa também foi encontrada no estudo de Monteiro, Ferreira e Teixeira (2009) que realizaram uma análise do IGD dos municípios do estado de Minas Gerais através da Análise Exploratória dos Dados (AED) e Testes de Correlação de Pearson, verificando relação negativa entre o aumento da população e das famílias beneficiadas e o IGD-M, concluindo que municípios maiores apresentam menores escores de IGD dado que possuem a menor relação de demanda e assistência relativa.

Um dos fatores que podem ser determinantes nessa correlação negativa é a centralização da gestão do Programa em municípios maiores. Enquanto em municípios menores a localização das famílias e a comunicação são favorecidas por um território menor, em situações de maior demanda a execução das ações do Programa por unidades centralizadoras (Cadastro Único, Secretaria de Saúde e Secretaria de Educação) pode ocasionar uma sobrecarga, sugerindo-se uma setorização da área.

Outra possível causa dessa relação negativa consiste na insuficiência da capacidade administrativa dos municípios brasileiros resultante das complexas relações entre a arrecadação e o contingente populacional dos municípios e da separação entre as tendências de concentração espacial dos recursos e de concentração das demandas por esses recursos, indicadas por Veloso e colaboradores (2011).

O estudo de Estrella e Ribeiro (2008), por meio de métodos quantitativos com 5.563 municípios brasileiros, concluiu que o IGD-M é negativamente relacionado com o IDHM-renda. Em outras palavras, quando o IGD-M aumenta, o IDHM-renda diminui, ou seja, os municípios com piores condições socioeconômicas apresentaram melhores resultados para o IGD-M. 
Esse achado aparentemente contraditório revela que a melhor qualidade de prestação da informação parte justamente para os municípios com indicadores sociais mais frágeis. Apesar de piores condições econômicas, esses municípios têm menor número de famílias beneficiárias. Podemos inferir que nos maiores municípios, apesar de possuírem redes assistenciais de serviços básicos maiores (em termos absolutos), elas não são suficientes para o monitoramento do programa porque o número de famílias a ser atendido é muito alto.

Apesar da compreensão da importância da estrutura dos municípios para o êxito da gestão da implementação do PBF, ainda são incipientes estudos sobre a implementação do Programa. Têm sido priorizados estudos de impacto que pretendem atender o maior questionamento que é a própria existência do Programa, porém pouco se avalia como os seus processos são operados. A principal pesquisa de avaliação realizada sobre o Programa é feita pelo governo federal: Avaliação de Impacto do Programa Bolsa Família I e II (Ministério de Desenvolvimento Social e Combate à Fome, 2007; Ministério de Desenvolvimento Social e Combate à Fome, 2012).

Estudos pontuais em várias localidades do Brasil sinalizam a insuficiência da rede assistencial na qual o Programa é implementado acarretando em limitação para o desenvolvimento das atividades obrigatórias em presença de maiores contingentes de famílias. As pesquisas descritas no quadro 4 utilizaram a metodologia do estudo de caso, sendo realizada pesquisa através de análise de documentos oficiais do PBF, entrevistas com gestores e profissionais que atuam nas diversas secretarias (saúde, educação e assistência social) e grupos focais com famílias beneficiárias.

Constata-se de modo geral que fragilidades da rede de serviços reincidentes nessas localidades têm implicações diretas no desempenho das atividades do Programa. A insuficiência quantitativa e de qualificação de recursos humanos, a insuficiência de recursos financeiros e institucionais, a falta de instância promotoras de descentralização, além da fragilidade ou ausência de uma rede de serviços sociais locais de educação e saúde são resultados que sinalizam os motivos pelos quais os desempenhos de gestão do Programa são menores quando se tem um maior número de famílias.

\section{Quadro 4}

Estudos de caso realizados na implementação do Programa Bolsa Família e principais resultados indicadores da insuficiência da rede assistencial

\begin{tabular}{|c|c|c|}
\hline Autor/Ano & Localidade & Principais resultados indicadores da insuficiência da rede assistencial \\
\hline Anesi (2010) & $\begin{array}{c}\text { Frederico } \\
\text { Westphalen e } \\
\text { Pelotas (RS) }\end{array}$ & $\begin{array}{l}\text { V Dificuldade de os municípios menores conviverem com a deficiência administrativa } \\
\text { e financeira para gestão da assistência social. }\end{array}$ \\
\hline Coelho (2009) & Manguinhos (RJ) & $\begin{array}{l}\text { Necessidade de repensar os fluxos de informação e decisão por meio do } \\
\text { fortalecimento de arenas locais onde técnicos, gestores, lideranças comunitárias e } \\
\text { população beneficiária possam compartilhar esforços para o fortalecimento de ações } \\
\text { intersetoriais. }\end{array}$ \\
\hline
\end{tabular}




\begin{tabular}{|c|c|c|}
\hline Autor/Ano & Localidade & Principais resultados indicadores da insuficiência da rede assistencial \\
\hline Martins (2008) & $\begin{array}{l}\text { Florianópolis } \\
\qquad \text { (SC) }\end{array}$ & $\begin{array}{l}\text { - Limitações e dificuldades da implementação em relação aos seguintes aspectos: } \\
\text { recursos humanos insuficientes, ausência de articulação entre a equipe técnica, falta } \\
\text { de conectividade entre a rede de serviços sociais e o programa, sendo esta insuficiente } \\
\text { para o atendimento das reais demandas das famílias. }\end{array}$ \\
\hline Pinto (2007) & Gameleira (PB) & $\begin{array}{l}\text { V Limitações na oferta de serviços e o acompanhamento das condicionalidades, } \\
\text { principalmente as de saúde. }\end{array}$ \\
\hline \multirow{3}{*}{ Dias (2008) } & \multirow{3}{*}{ Bacabal (MA) } & $\begin{array}{l}\text { V Nem todas as instâncias responsáveis pelo acompanhamento das condicionalidades } \\
\text { eram atuantes no município. }\end{array}$ \\
\hline & & $\begin{array}{l}\text { Vão houve mudanças na estrutura de atendimento das famílias beneficiárias pelas } \\
\text { instâncias que já atuam, permanecendo um acompanhamento burocrático das } \\
\text { condicionalidades. }\end{array}$ \\
\hline & & $\begin{array}{l}\text { - O processo intersetorial entre as ações do Programa no município e as outras políticas } \\
\text { públicas ainda não estava consolidado. }\end{array}$ \\
\hline & & v Dificuldade para executar um programa social intersetorial. \\
\hline Monnerat (2009) & Niterói (RJ) & $\begin{array}{l}\text { Vonjunto de problemas concretos relacionados com a condução, coordenação } \\
\text { e gerenciamento do PBF que afetam o processo de implementação das } \\
\text { condicionalidades da saúde. }\end{array}$ \\
\hline Ferreira (2009) & Manguinhos (RJ) & $\begin{array}{l}\text { Fragilidades institucionais como: pouca qualificação dos profissionais, ausência } \\
\text { de incentivos, falta de recursos humanos, ênfase na questão burocrática e oferta } \\
\text { insuficiente de ações e serviços de saúde. }\end{array}$ \\
\hline
\end{tabular}

Fonte: Elaboração dos autores a partir dos estudos citados.

A correlação positiva entre o IGD saúde e a Validação de Cadastros, a Atualização de Cadastros e o IGD educação pode ser interpretada como necessidade da gestão integrada do Programa. Os indicadores de Validação de Cadastro e Atualização de cadastros permitem uma melhor implementação da condicionalidade da saúde, pois a dinâmica de localização e monitoramento da família é estreitamente dependente de informações disponíveis atualizadas.

O monitoramento da saúde acontece em uma periodicidade de seis meses, denominado vigência, no qual os agentes comunitários de saúde recebem mapas de acompanhamento com endereços das famílias do programa da sua respectiva unidade de saúde. Caso esse dado não seja compatível com a situação real, haverá uma dificuldade na localização dessa família.

Burlandy e Salles-Costa (2009) evidenciam que em contexto de desigualdade mais acentuada, como ocorre no Brasil, famílias de baixa renda podem ter diferenças no acesso de bens e serviços públicos de acordo com a localização do domicílio. Para os autores, as famílias residentes nas áreas urbanas ou em determinados bairros do município tendem a ter mais acesso a bens e serviços mesmo sendo tão pobres quanto outras que residam em áreas onde há menor disponibilidade desses bens.

Quanto à correlação positiva encontrada entre IGD saúde e IGD educação, pode-se inferir que, quanto mais as crianças permanecem nas escolas, exigência da condicionalidade da 
educação, esse fato levará a uma maior permanência da família naquela localidade, levando a uma localização mais ágil dos serviços de saúde aos beneficiários em virtude de menores mudanças de endereço.

A respeito da interdependência dos processos do PBF evidenciada pela correlação positiva entre os componentes, é pertinente apontar que tal evidência pode ser usada de modo estratégico para a gestão do Programa, enfatizando de forma clara a necessidade da intersetorialidade. Nesse sentido, é possível destacar como um avanço a criação do Fórum Intersetorial e Intergovernamental de Condicionalidades do PBF, por meio da Portaria Interministerial MDS/MEC/MS n 2/2009, formado por representantes do MDS, do MEC, do MS e das entidades de representação de estados e municípios nas três áreas. Esse espaço deve propor medidas sinérgicas para o gerenciamento desta complexa política.

O objetivo das condicionalidades seria uma dupla responsabilização das famílias pelo compromisso assumido e do poder público em assegurar a oferta desses serviços básicos. Além dos fatores limitantes já mencionados, a estrutura das duas maiores políticas sociais (educação e saúde) pouco favorece o exercício das condicionalidades. Como dito anteriormente, a condicionalidade da saúde é em grande parte dos municípios articulada pelo programa Estratégia Saúde da Família, que não está presente em todas as localidades. Isso implica diretamente que o IGD saúde tenha fracos resultados, mesmo representando apenas a frequência de idas da família à unidade.

Lício, Mesquita e Curralero (2011) enfatizam que, para as ações direcionadas ao público mais pobre, caracterizado pela maior dificuldade de acesso aos serviços de políticas setoriais, existe a necessidade da valorização do princípio da equidade nas políticas de caráter universal, pois se verifica um grande desafio no sentido de pautar e priorizar o público atendido pelo PBF mediante a abertura de novos espaços de inclusão e ampliação dos espaços já existentes.

Ressalta-se dessa forma que as condicionalidades do PBF devem ser estrategicamente racionalizadas para viabilizar o acesso de pessoas mais pobres ao circuito de serviços essenciais. O planejamento deve ser direcionado a fim de superar elementos que inviabilizam o acesso desse contingente importante da população aos circuitos de oferta de serviços sociais. Devem ser minimizados elementos que dificultam o atendimento à população de baixa renda. Entre os principais entraves da implementação das condicionalidades se destacam, principalmente, o baixo número de unidades de atendimento, implicando alta demanda relativa aos serviços, a distribuição espacial dos serviços não compatível com as demandas concentradas principalmente em bolsões de pobreza em áreas urbanas e a baixa capacidade gerencial dos municípios brasileiros.

\section{Considerações finais}

As grandes regiões urbanas, em sua maioria, concentram grandes bolsões de pobreza, regiões marginalizadas da sociedade e de serviços básicos de promoção aos direitos humanos elementares. O PBF pretende por meio das condicionalidades promover uma aproximação dessa 
população com os serviços de educação e saúde. No entanto, a rede de assistência ainda não está preparada para atender à demanda gerada pelo Programa, mesmo que a procura seja por ações básicas. Na educação, a simples frequência escolar e, na saúde, o acesso aos serviços que já deveriam ser universalizados de imunização, pré-natal e acompanhamento nutricional, ainda não constituem rotina de grupos sociais vulneráveis quanto à renda.

Esta pesquisa conclui que o maior número de famílias beneficiárias do PBF no Nordeste leva a um decréscimo dos seus indicadores de monitoramento. Tal informação levanta a discussão sobre a real capacidade de os municípios implementarem o Programa na sua totalidade, desde o cadastro dos beneficiários, a atualização deste e o cumprimento de condicionalidades. Evidentemente, essa constatação não significa dizer que o descumprimento das condicionalidades deve ser motivo para pôr em xeque o Programa. Mas aponta para as fragilidades de gestão nos municípios e coloca um enorme desafio para o sucesso da política que tenta articular o PBF a outras ações igualmente importantes para a cidadania como a saúde e a educação. Uma iniciativa como o PBF impõe naturalmente uma gestão descentralizada de modo a fortalecer a articulação entre os entes envolvidos no processo.

A descentralização administrativa das ações básicas do PBF em municípios grandes é um primeiro passo para qualificar as ações do programa. Os processos envolvidos em cadastro e sua atualização precisam chegar às diferentes localidades, procurando de fato os verdadeiros beneficiários do programa. Quanto às condicionalidades, é necessária uma integração das ações destes segmentos com o cadastro único, pouco favorecida por estes utilizarem sistemas de informação diferentes, oriundos de programas anteriores que criaram o PBF.

A conclusão de que um maior número de beneficiários leva a uma diminuição dos subindicadores do Fator de Operação levanta a discussão sobre a real capacidade de os municípios implementarem o Programa na sua totalidade, desde o cadastro dos beneficiários e sua atualização, até o cumprimento de condicionalidades. Essa constatação aponta para as fragilidades de gestão nos municípios e coloca um enorme desafio para o sucesso da política que tenta articular o PBF a outras ações igualmente importantes para a cidadania.

Acredita-se que a necessidade de implementação inicial do Programa em uma estrutura previamente existente o viabilizou. Porém é notório que sua expansão, resultante do expressivo aumento de seus beneficiários ao longo de 10 anos de sua existência, exige uma apreciação da real capacidade de gestão dos municípios para assumirem a contento suas atividades. Trata-se de uma necessidade imperiosa para que o Programa supere suas fragilidades e possa contribuir efetivamente para a construção de uma cidadania plena e capaz de romper o círculo vicioso da pobreza.

\section{Referências}

ANESI, Sidinei A. Diferenças da gestão e as repercussões sociais do Programa Bolsa Família nos municípios de Frederico Westphalen e Pelotas, RS. Dissertação (mestrado) — Programa de Pós-Graduação em Política Social, Universidade Católica de Pelotas, Pelotas, 2010. 
BOSCHETTI, Ivanete. Seguridade social e trabalho: paradoxos da construção das políticas de previdência e assistência social no Brasil. Brasília: Letras Vivas; Editora UnB, 2006.

BRASIL. Decreto no 5.209 de 17 de setembro de 2004a. Regulamenta o Programa Bolsa Família. Disponível em: <www.planalto.gov.br>. Acesso em: 16 dez. 2010.

BRASIL. Lei no 10.836 de 9 de janeiro de 2004b. Institui o Programa Bolsa Famúlia. Disponível em: <www.planalto.gov.br>. Acesso em: 16 dez. 2010.

BURLANDY, Luciene; SALLES-COSTA Rosana. Segurança alimentar e nutricional: concepções e desenhos de investigação. In: KAC, Gilberto; SCHIERI; Rosely; GIGANTE, Denise P. (Org.). Epidemiologia nutricional. Rio de Janeiro: Fiocruz; 2007. p. 485-499.

CASTRO, Henrique C. O. et al. Percepções sobre o Programa Bolsa Família na sociedade brasileira. Opinião Pública, v. 15, n. 2, p. 333-355, nov. 2009.

CHIECHELSKI, Paulo C. S. Sistemática de avaliação para avaliação de municípios que implantaram o programa Bolsa Família. Tese (doutorado) — Programa de Pós-graduação em Serviço Social, Pontifícia Universidade Católica do Rio Grande do Sul, Porto Alegre, 2007.

CICERO, Flávio; SILVA, Joana; PROENÇA, Rafael P. Condicionalidades, desempenho e percurso escolar de beneficiários do Programa Bolsa Família. In: NERI, Marcelo C.; CAMPELLO, Tereza (Org.). Programa Bolsa Família: uma década de inclusão e cidadania. Brasília: Ipea, 2013.

COBO, Barbara. Políticas focalizadas de transferência de renda: contextos e desafios. São Paulo: Cortez, 2012.

COELHO, Ângela V. A. G. A construção da intersetorialidade no Programa Bolsa Família em Manguinhos, no Rio de Janeiro. Dissertação (mestrado) - Escola Nacional de Saúde Pública. Rio de Janeiro, 2009.

COSTA, Frederico L.; CASTANHAR, José C. Avaliação de programas públicos: desafios conceituais e metodológicos. Rev. Adm. Pública, v. 37, n. 5, p. 969-992, set./out. 2003.

CURRALERO, Cláudia R. B.; ALONSO, Ana L. F. O Índice de Gestão Descentralizada (IGD) e o Sistema de Condicionalidades (Sicon) como ferramentas de gestão intersetorial do Programa Bolsa Família. In: CONGRESSO CONSAD DE GESTÃO PÚBLICA, IV, 2011, Brasília.

DIAS, Magda N. A. O programa Bolsa Família no munícipio de Bacabal-MA: avaliação do processo de implementação com foco nas condicionalidades. Dissertação (mestrado) — Programa de PósGraduação em Políticas Públicas, Universidade Federal do Piauí, Teresina, 2008.

DRAIBE, Sônia M. Avaliação de implementação: esboço de uma metodologia de trabalho em políticas públicas. In: BARREIRA, Maria C.; CARVALHO, Maria C. Tendências e perspectivas na avaliação de políticas e programas sociais. São Paulo: IEE/PUC-SP, 2000.

ESTRELLA, Juliana; RIBEIRO, Leandro M. Qualidade da gestão das condicionalidades do Programa Bolsa Família: uma discussão sobre o índice de gestão descentralizada. Rev. Adm. Pública, v. 42, n. 3, p. 625-641, jun. 2008. 
FERREIRA, Milena N. Programas de transferência condicionada de renda e acesso aos serviços de saúde: um estudo da experiência do Programa Bolsa Família em Manguinhos. Dissertação (mestrado) Escola Nacional de Saúde Pública Sergio Arouca, Rio de Janeiro, 2009.

GARCIA, Ronaldo C. Subsídios para organizar avaliações de ação governamental. Texto para discussão, Ipea, Brasília, 2000.

LICIO, Elaine C.; MESQUITA, Camile, S.; CURRALERO, Claúdia R. Desafios para coordenação intergovernamental do programa Bolsa Família. Revista de Administração Eletrônica, v. 51, n. 5, p. 458-470, set./out. 2011.

MAGALHÃES JUNIOR, Helvécio M.; JAIME, Patricia C.; LIMA, Ana M. C. O papel do setor saúde no Programa Bolsa Família: histórico, resultados e desafios para o Sistema Único de Saúde. In: NERI, Marcelo C.; CAMPELLO, Tereza (Org.). Programa Bolsa Família: uma década de inclusão e cidadania. Brasília: Ipea, 2013. p. 93-107.

MARTINS, Valter. O processo de implementação e gestão do Programa Bolsa Família em Florianópolis. Dissertação (mestrado) — Programa de Pós-graduação em Serviço Social, Universidade Federal de Santa Catarina, Florianópolis, 2008.

MINISTÉRIO DA SAÚDE. Histórico de cobertura da saúde da família. Departamento de Atenção Básica do Ministério da Saúde. Disponível em: < http://dab.saude.gov.br/portaldab/historico_cobertura_sf.php>. Acesso em: 20 mar. 2014.

MINISTÉRIO DA SAÚDE. Relatório do Colóquio sobre Acompanhamento das Condicionalidades de Saúde do Programa Bolsa Família. Coordenação-Geral de Alimentação e Nutrição — CGAN, Brasília, 2011.

MINISTÉRIO DO DESENVOLVIMENTO SOCIAL E COMBATE À FOME. Avaliação de Impacto do Programa Bolsa Família: 1aㅡ Rodada (AIBF I). Brasília, 2007.

MINISTÉRIO DO DESENVOLVIMENTO SOCIAL E COMBATE À FOME. Avaliação de Impacto do Programa Bolsa Família: 2ª Rodada (AIBF II). Brasília, 2012.

MINISTÉRIO DO DESENVOLVIMENTO SOCIAL E COMBATE À FOME. Caderno do IGD-M: informativo sobre o Índice de Gestão Descentralizada Municipal do Programa Bolsa Família. Secretaria Nacional de Renda da Cidadania. Brasília, 2012.

MINISTÉRIO DO DESENVOLVIMENTO SOCIAL E COMBATE À FOME. Portaria CM/MDS no 321 de 29 de setembro de 2008. Regulamenta a gestão das condicionalidades do Programa Bolsa Família. Disponível em: <www.mds.gov.br>. Acesso em: 20 out. 2011.

MINISTÉRIO DO DESENVOLVIMENTO SOCIAL E COMBATE À FOME. Programa Bolsa Família. Legislação e Instruções. Disponível em: <www.mds.gov.br/bolsafamilia/menu_superior/legislação> . Acesso em: 20 out. 2011.

MONNERAT, Giselle L. Transferência condicionada de renda, saúde e intersetorialidade: lições do Programa Bolsa Família. Tese (doutorado) - Escola Nacional de Saúde Pública Sergio Arouca, Rio de Janeiro, 2009. 
MONTEIRO, Doraliza A. A.; FERREIRA, Marco A. M.; TEIXEIRA, Karla M. D. Determinantes da gestão do Programa Bolsa Família: análise do índice de gestão descentralizada em Minas Gerais. Saúde e Sociedade, v. 18, n. 2, p. 615-632, jun. 2009.

MOTA, Ana E.; AMARAL, Angela S.; PERUZZO, Juliane F. O novo desenvolvimentismo e as políticas sociais na América Latina. In: MOTA, Ana E. (Org.). Desenvolvimentismo e construção da hegemonia: crescimento econômico e reprodução da desigualdade social. São Paulo: Cortez, 2012.

PAIVA, Luiz H.; FALCÃO, Thiago; BERTHOLO, Leticia. Do Bolsa Família ao Brasil sem Miséria: um resumo do percurso brasileiro recente na busca da superação da pobreza extrema. In: NERI, Marcelo C.; CAMPELLO, Tereza (Org.). Programa Bolsa Família: uma década de inclusão e cidadania. Brasília, Ipea, 2013. p. 25-46.

PASTORINI, Alejandra. Assistencialização da proteção social e os programas de combate a pobreza no Brasil. Revista Ser Social, v. 1, n. 18, p. 253-284, jan./jun. 2006.

PEDROSO, Marcel M.; CALMON, Paulo C. P.; BANDEIRA, Ludmila F. O uso da análise envoltória de dados para avaliação da gestão do Programa Bolsa-Família. Comunicação em Ciências da Saúde, v. 1, n. 20, p. 37-44, 2009.

PINTO, Fernanda C. L. Segurança alimentar e nutricional: o Programa Bolsa Família na realidade de um município da zona da mata pernambucana. Dissertação (mestrado) — Programa de PósGraduação em Nutrição, Universidade Federal de Pernambuco, Recife, 2007.

SANTOS, Cláudia R. B.; MAGALHAES, Rosana. Pobreza e política social: a implementação de programas complementares do Programa Bolsa Família. Ciênc. Saúde Coletiva, v. 17. n. 5, p. 12151224, maio 2012.

SILVA, Ana P. Q. Política de transferência de renda e desenvolvimento local: o Programa Bolsa Família no município de Pedra Grande/RN. Dissertação (mestrado) — Programa de Pós-Graduação em Serviço Social, Universidade Federal do Rio Grande do Norte, Natal. 2008.

SOARES, Sergei; SÁTYRO, Natália. O programa Bolsa Família: desenho institucional, impactos e possibilidades futuras. Texto para discussão n. 1424. Ipea, Brasília, out. 2009.

SOUZA, André P. Políticas de distribuição de Renda no Brasil e o Bolsa Família. In: BACHA, Edmar L.; SCHWARTZMAN, Simon (Org.). Brasil: a nova agenda social. Rio de Janeiro: LCT, 2011. p. 167-186.

SUBIRATS, Joan. Análisis de políticas públicas y eficácia de la administración. Madri: Ministerio para las Administraciones Públicas, 1994.

VELOSO, João F. A. et al. Uma visão inicial dos subsistemas da gestão municipal. In: VELOSO, João F. A. (Org.). Gestão municipal no Brasil: um retrato das prefeituras. Brasília: Ipea, 2011. p. 11-39.

ZIMMERMANN, Clóvis R. Os programas sociais sob a ótica dos direitos humanos: o caso do Bolsa Família do governo Lula no Brasil. Sur. Revista Internacional de Direitos Humanos, v. 3, n. 4, p. 149-159, jun. 2006. 
Fábio Resende de Araújo é doutorando em administração pela Universidade Federal do Rio Grande do Norte (UFRN) e professor assistente da UFRN. E-mail: resende_araujo@hotmail.com.

Maria Arlete Duarte de Araújo é doutora pela Fundação Getulio Vargas (FGV-SP) e professora titular da Universidade Federal do Rio Grande do Norte (UFRN). E-mail: mariaarlete1956@gmail.com.

Fabia Jaiany Viana de Souza é mestre em contabilidade pelo Programa Multi-institucional e Inter-regional UnB/UFPB/UFRN e contadora do Instituto Federal de Educação, Ciência e Tecnologia do Rio Grande do Norte (IFRN). E-mail: fabiajaiany@yahoo.com.br.

Diego Fiel Santos é mestre em administração pela Universidade Federal do Rio Grande do Norte (UFRN) e professor assistente da Universidade Federal de Juiz de Fora (UFJF). E-mail: diegoufs@yahoo.com.br.

Murilo Barreto Santana é doutorando em administração pela Universidade Federal do Rio Grande do Norte (UFRN) e professor assistente da Universidade Estadual de Santa Cruz (Uesc). E-mail: muriloadm@hotmail.com. 
